\title{
EVALUATION OF TREATMENT MODALITIES OF CONGENITAL NASOLACRIMAL DUCT OBSTRUCTION IN PAEDIATRIC PATIENTS FROM A TERTIARY EYE CARE CENTRE
}

\author{
Sanjay Kai1 , Bhavani Raina², Pallavi Sharma ${ }^{3}$
}

${ }^{1}$ Associate Professor, Department of Ophthalmology, Government Medical College, Jammu, Jammu and Kashmir.

${ }^{2}$ Lecturer, Department of Ophthalmology, Government Medical College, Jammu, Jammu and Kashmir.

${ }^{3}$ Registrar, Department of Ophthalmology, Government Medical College, Jammu, Jammu and Kashmir.

\section{BACKGROUND}

\section{ABSTRACT}

Congenital nasolacrimal duct obstruction is a condition where there is non-canalisation of nasolacrimal duct at its lower end at the level of valve of Hasner. It is the most common cause of epiphora in new-borns occurring in $20 \%-30 \%$ of the new-borns. About $1 \%-6 \%$ of these children become symptomatic and the most common symptom is epiphora.

Aims and Objectives-

- $\quad$ To study the demographic profile of the patients presenting with congenital nasolacrimal duct obstruction.

- To study the outcome of treatment modalities in patients with congenital nasolacrimal duct obstruction.

\section{MATERIALS AND METHODS}

This is a prospective observational study. A minimum of 110 eyes of children aged $<4$ years with clinical diagnosis of congenital nasolacrimal duct obstruction with classical symptoms of epiphora and regurgitation of watering and discharge or both on pressure at lacrimal sac area were included in the study. Each patient was subjected to detailed history taking regarding the symptoms and duration of the symptoms. A careful and detailed examination of the eye was undertaken. All the patients those who were of age less than six months were first subjected to conservative treatment of lacrimal massaging at home after demonstration at hospital, thereafter, those who failed to respond to treatment upto the age of six months were subjected to syringing and probing under general anaesthesia. All cases were reviewed at $4^{\text {th }}, 8^{\text {th }}$ and $12^{\text {th }}$ week. The patient was said to be cured if there was no recurrence of symptoms or discharge even after stoppage of antibiotics and massage for two weeks.

\section{RESULTS}

Out of 110 patients, $62(56.3 \%)$ were males and $48(43.6 \%)$ were females.

Laterality- In 51 (46.3\%) left eye was involved, in 20 (18.1\%) right eye was involved and in 39 (35.4\%) there was bilateral involvement.

Mean Age- Mean age of presentation was 3.9 months.

Socio-Economic Status- 36 (32.7\%) children belonged to Poor socio-economic strata. 40 (36.3\%) patients were from Middle socioeconomic strata and $34(30.9 \%)$ patients belonged to Higher socio-economic strata.

Referral Pattern- 60 (54.5\%) patients were referred by paediatricians after initial treatment, $12(10.9 \%)$ patients were brought by their parents on their own. 38 (34.5\%) patients were referred by Registered Medical Practitioners.

Success Rate- 102 (92.7\%) of the children were relieved of their symptoms within 12 weeks of conservative treatment. Only 8 children, i.e. $7.2 \%$ who could not get relieved of their symptoms even after the age of 6 months. Out of these 8 patients, symptoms were relieved in 5 patients with single syringing and probing only. Two patients required syringing and probing twice to get their symptoms relieved and only one patient was not cured.

\section{CONCLUSION}

With this study, we conclude that nasolacrimal duct massage has a very high success rate and should be started as early as possible to be more effective. The syringing and probing also have high success rate and should be started as early as six months of age to avoid the morbidity of epiphora and risk of dacryocystitis.

\section{KEY WORDS}

Paediatric Epiphora, Congenital Nasolacrimal Duct Block, Probing.

HOW TO CITE THIS ARTICLE: Kai S, Raina B, Sharma P. Evaluation of treatment modalities of congenital nasolacrimal duct obstruction in paediatric patients from a tertiary eye care centre. J. Evolution Med. Dent. Sci. 2018;7(19):2333-2337, DOI: $10.14260 /$ jemds/2018/526

\section{BACKGROUND}

Congenital nasolacrimal duct obstruction is a condition where there is non-canalisation of nasolacrimal duct at its lower end at the level of valve of Hasner and it manifests at

'Financial or Other Competing Interest': None.

Submission 21-03-2018, Peer Review 20-04-2018,

Acceptance 27-04-2018, Published 07-05-2018.

Corresponding Author:

Dr. Bhavani Raina,

\#309 B, Sector-1, Durga Nagar,

Jammu-180013, Jammu and Kashmir, India.

E-mail: bhavaniraina@yahoo.co.in

DOI: $10.14260 /$ jemds $/ 2018 / 526$ about third week of life. It is the most common cause of epiphora in new-borns occurring in $20 \%-30 \%$ of the newborns. ${ }^{1,2}$ In most of these infants, it resolves spontaneously even without any treatment. However, about $1 \%-6 \%$ of these children become symptomatic by about third week of life and the most common symptoms are epiphora, mucoid or mucopurulent discharge and rarely they may present with acute dacryocystitis. Conservative treatment in the form of nasolacrimal sac massage if done properly resolves the block in $90 \%$ children in the first year only. ${ }^{3-7}$ Most of these infants are usually brought to paediatrician first with symptoms of epiphora and discharge and rarely acute dacryocystitis. Only after the failure of antibiotic therapy in the form of drops they 
are usually referred to the ophthalmologist. It has been reported in literature that delaying probing beyond one year of age decreases the success rate and at the same time there are also reports in literature, which claims that the success rate is not affected even if the probing is done after the age of two years. So there are no fixed guidelines available in the literature for the age at which the syringing and probing should be attempted. As reported in various studies most of the ophthalmologists usually attempt it in between the age of 9 - 12 months, $4,5,6$ but waiting so long subjects these children to lot of morbidity due to constant epiphora and discharge and psychological trauma to parents. This also exposes these children to the risk of dacryocystitis and chronic low-grade infections of lacrimal sac and nasolacrimal duct, which further decreases the chances of positive outcome with both nasolacrimal duct massage and syringing and probing if required in future.8,9 So keeping all these facts in mind, we decided to keep the cut-off age for syringing and probing to six months. In case the patient fails to respond to repeated syringing and probing, then the last resort in such cases is dacryocystorhinostomy which is usually attempted at the age of three to four years so as to avoid the interference with normal bone development. There are various factors which are associated with failure of syringing and probing like improper technique, late age of probing, anatomical variation, inferior turbinate hypertrophy and other nasal pathologies. There have been recent advances to treat such failed and complex cases. Endoscopic visualisation and endoscopic assisted probing have helped in achieving better success rate in such complex cases (94\% - 97\%). Techniques like balloon catheter dilatation, silicone intubation and inferior turbinate fracture further improves the results in such complex cases.

\section{Nasolacrimal Duct Massage}

Moderate pressure is applied over the medial canthal region with the finger and the common canaliculi is blocked so as to increase the hydrostatic pressure inside the sac. Then gently the finger is moved downward on the side of nose to transmit the fluid pressure inside the sac towards the lower end of the duct where the block is located. This procedure is repeated as 5 - 10 stokes at a time and about thrice a day. Mothers are advised to keep the finger nail short to avoid any inadvertent injury to the eye and also advised to apply some lubricant lotion to finger before doing the procedure.10

\section{Anatomy of Nasolacrimal Duct}

Nasolacrimal duct have two parts, superior intraosseous part which is about $12 \mathrm{~mm}$ and inferior membranous part which is about $5 \mathrm{~mm}$. The diameter of the bony part is about $1 \mathrm{~mm}$ and is directed downward and posterolaterally in the maxillary bone, while the membranous part run in the nasal mucosa and open in inferior meatus of nasal cavity. The lower end opening of the duct is guarded by a valve called as valve of Hasner. This valve prevents regurgitation of nasal secretions into the duct. This valve has been found to be imperforate in $70 \%$ of new-borns and in most of them it spontaneously opens up during the first month of life. In remaining where it fails to open, the infants present with signs and symptoms of congenital nasolacrimal duct obstruction.

\section{Syringing and Probing}

The procedure was performed under general anaesthesia. To begin with first the upper puncta was dilated with a punctum dilator. A Bowman's probe ( 0 and 00 ) was used to negotiate the punctum and advanced till the hard stop felt. After that the probe was rotated 90 degrees superiorly and pushed posteriorly, inferiorly and slightly laterally into the nasolacrimal duct. It is further advanced till a membranous resistance is felt, which is gently breached to relieve the block. This was confirmed with a metallic touch by an instrument passed through the nasal cavity and also by subsequent syringing. The syringing saline was coloured with $2 \%$ fluorescein dye. Flow of saline in throat was detected by a suction catheter placed in throat.

\section{Aims and Objectives}

- To study the demographic profile of the patients presenting with congenital nasolacrimal duct obstruction.

- $\quad$ To study the outcome of treatment modalities in patients with congenital nasolacrimal duct obstruction.

\section{MATERIALS AND METHODS \\ Study Design \\ A prospective observational study.}

\section{Study Setting \\ A hospital-based study.}

A total of 110 eyes of children aged $<4$ years with clinical diagnosis of congenital nasolacrimal duct obstruction with classical symptoms of epiphora and regurgitation of pus on pressure at lacrimal sac area were included in the study. Each patient was subjected to detailed history taking regarding the symptoms and duration of the symptoms. A careful and detailed examination of the eye was undertaken. All the patients those who were of age less than six months were first subjected to conservative treatment of lacrimal massaging at home after demonstration at hospital, thereafter those who failed to respond to treatment upto the age of six months were subjected to syringing and probing under general anaesthesia. All cases were reviewed at $4^{\text {th }}, 8^{\text {th }}$ and $12^{\text {th }}$ week. The patient was said to be cured if there was no recurrence of symptoms or discharge even after stoppage of antibiotics and massage for two weeks.

\section{Inclusion Criteria}

All cases with history of watering and discharge between the ages of 2 weeks to 4 yrs.

\section{Exclusion Criteria}

- Corneal abrasion.

- Birth trauma.

- Congenital Glaucoma.

- Keratitis.

\section{RESULTS \\ Gender Distribution}

Out of 110 patients, $62(56.3 \%)$ were males and 48 (43.6\%) were females (Figure 1). 


\section{Laterality}

In 51 (46.3\%) left eye was involved. In 20 (18.1\%) right eye was involved and in 39 (35.4\%) there was bilateral involvement (Figure 2).

\section{Mean Age}

Mean age of presentation was 3.9 months.

\section{Socio-Economic Status}

$36(32.7 \%)$ children belonged to Poor socio-economic strata. $40(36.3 \%)$ patients were from Middle socio-economic strata and 34 (30.9\%) patients belonged to Higher socio-economic strata (Figure 3). Referral Pattern: 60 (54.5\%) patients were referred by paediatricians after initial treatment, $12(10.9 \%)$ patients were brought by their parents on their own. 38 (34.5\%) patients were referred by Registered Medical Practitioners (Figure 4).

\section{Conservative Management}

$102(92.7 \%)$ of the children were relieved of their symptoms progressively over the period of 12 weeks of conservative treatment with lacrimal massage and antibiotic drops. There were only 8 children, i.e. $7.2 \%$ who could not get relieved of their symptoms even after the age of 6 months and required intervention in the form of syringing and probing under general anaesthesia. Out of these 8 patients treated with syringing and probing, symptoms were relieved in 5 patients with single syringing and probing only. Two patients required syringing and probing twice to get their symptoms relieved and only one patient was declared not cured.

\begin{tabular}{|c|c|c|}
\hline Symptoms & $\mathbf{N = 1 1 0}$ & \% \\
\hline Epiphora & 15 & $13.6 \%$ \\
\hline Mucoid discharge & 32 & $29 \%$ \\
\hline $\begin{array}{c}\text { Mucopurulent } \\
\text { discharge }\end{array}$ & 63 & $57.2 \%$ \\
\hline \multicolumn{2}{|c|}{ Table 1. Presenting Complaints } \\
\hline
\end{tabular}

\begin{tabular}{|c|c|c|}
\hline & Cured & $\%$ \\
\hline 4 Weeks & 26 & $25.4 \%$ \\
\hline 8 Weeks & 66 & $64.7 \%$ \\
\hline 12 Weeks & 10 & $9.8 \%$ \\
\hline Total & 102 & \\
\hline
\end{tabular}

\begin{tabular}{|c|c|}
\hline & Number of Cases \\
\hline First Probing & 5 \\
\hline Second Probing & 2 \\
\hline Not Cured & 1 \\
\hline Total & 8 \\
\hline \multicolumn{2}{|c|}{ Table 3. Results of Syringing and Probing } \\
\hline
\end{tabular}

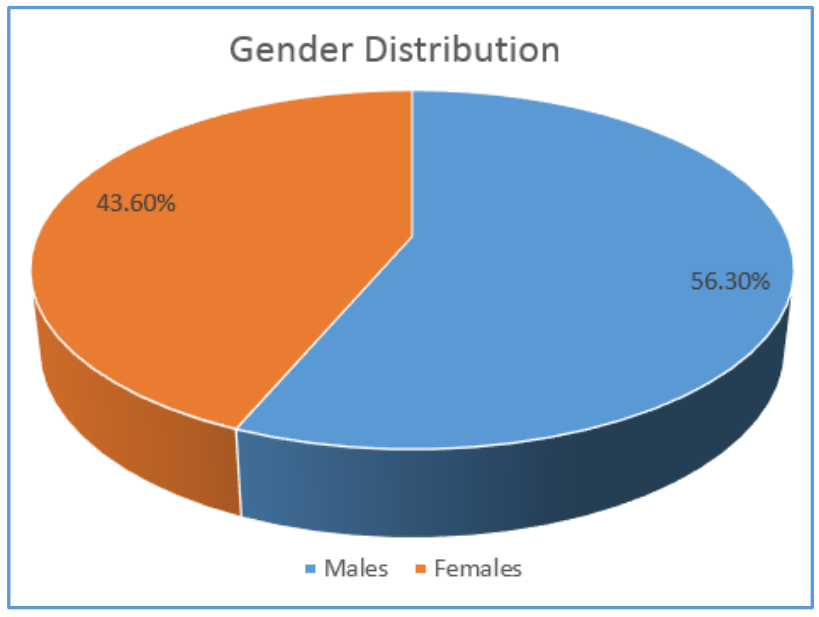

Figure 1

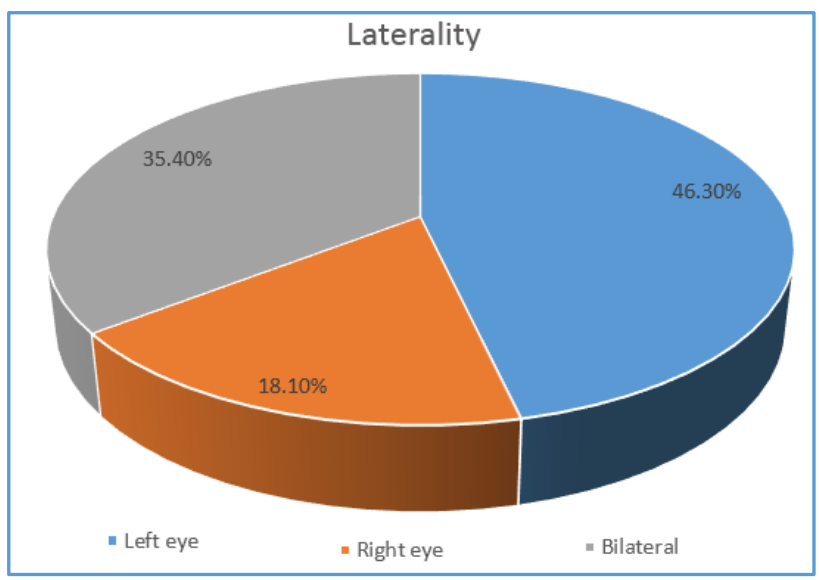

Figure 2

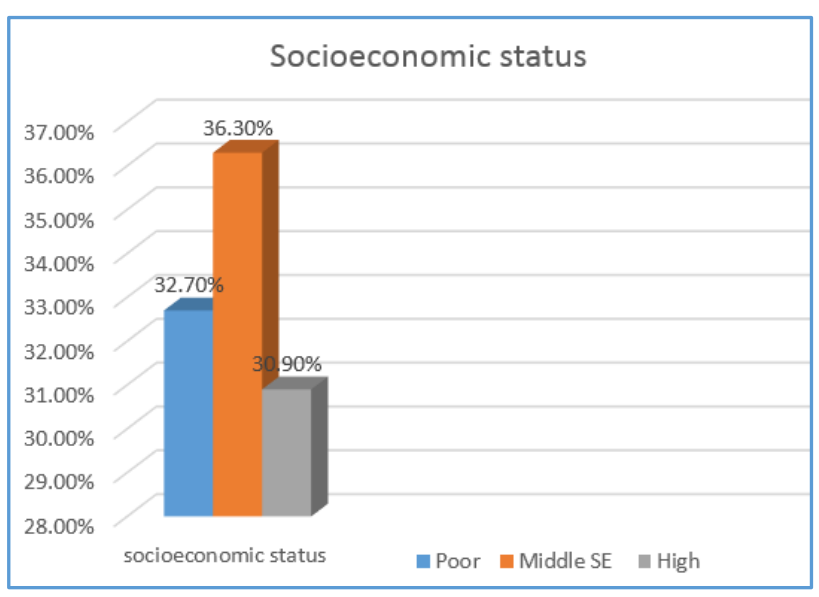

Figure 3 


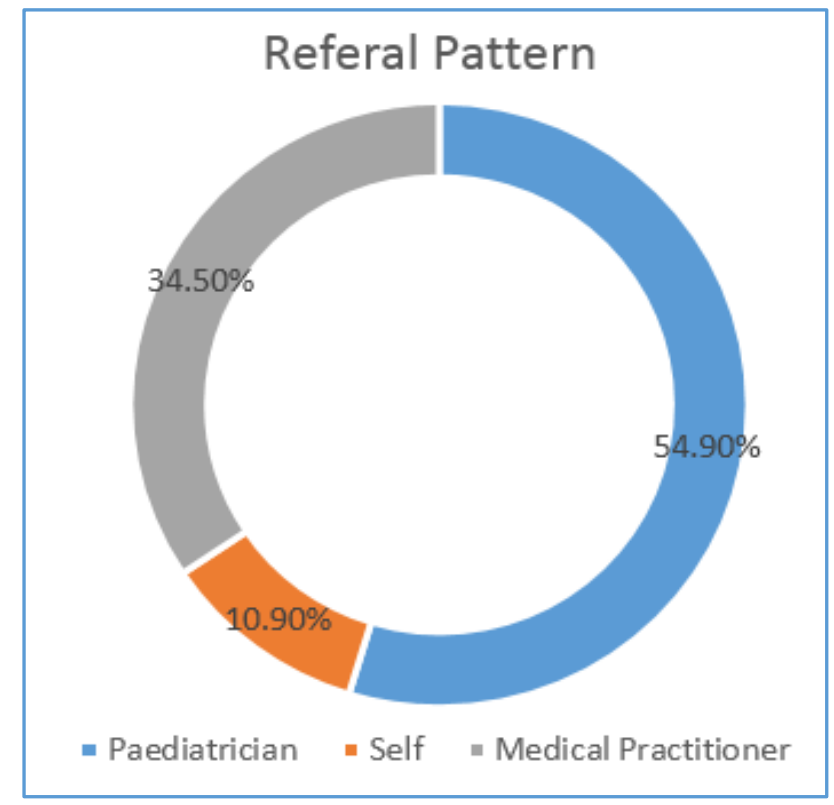

Figure 4

\section{DISCUSSION}

Paediatric epiphora is very common symptoms in new-born children and seen in about $20 \%-30 \%$ new-born infants. ${ }^{1,2}$ One of the most common cause is congenital nasolacrimal duct blockage. Various modalities of treatments like lacrimal sac massage, syringing and probing and finally dacryocystorhinostomy have been used to treat this problem with variable success rate reported in various studies. Conservative treatment in the form of lacrimal sac massage is the treatment of first choice by most of the ophthalmologists as it is non-invasive, cheap and can be done by mothers themselves.

\section{Gender}

In our study, $62(56.3 \%)$ were males and $48(43.6 \%)$ were females. Nazaullah Khan et al (2006) ${ }^{11}$ reported $64 \%$ male and $36 \%$ female distribution. Halipota et al ${ }^{12}$ reported that $65 \%$ of cases were males and $35 \%$ females.

\section{Laterality}

In our study, $64.4 \%$ patients had unilateral presentation and $35.4 \%$ had bilateral presentation. Right eye was involved in $18.1 \%$ and left eye was involved in $46.3 \%$ cases. Halipota et al (2000)12 reported $71 \%$ cases as unilateral and $29 \%$ cases as bilateral. Babu et al (2013), 81\% of cases with unilateral presentation and $19 \%$ of cases with bilateral involvement.

\section{Socio-Economic Status}

There was no association seen with any particular socioeconomic group.

\section{Referral Pattern}

Most of our patients were referred by either paediatrician or registered medical practitioners $((89 \%)$. This could be due to the fact that ours is a tertiary eye care hospital and lot of patients from far flung areas are routinely referred by peripheral health care centres.

\section{Presentation}

Most of our patients presented with mucopurulent discharge (57.2\%) followed by mucoid discharge (29\%) and epiphora (13.6\%) (Table 1). On history taking, it was found that most of these patients were put on antibiotics drops by the treating health care personal and only referred when alarmed by appearance of mucopurulent discharge or non-resolution of discharge despite antibiotic treatment. When asked regarding the lacrimal sac massage technique, most of these patients were either not aware of the technique or doing it wrongly by just massaging the nasal bridge. So awareness among the health care professionals regarding the correct technique of lacrimal massage is very important.

\section{Success Rate}

The overall success rate of nasolacrimal duct massage was 102 out of total 110 patients, i.e. 92.6\% (Table 2). Most of our patients responded to this form of treatment over the period of 12 weeks. There were only eight patients out of one hundred and ten patients who did not respond to this form of treatment. Out of these 8 patients who did not respond to treatment, 6 patients were more than the age of 6 months. This finding highlights the fact that with increasing age, effectiveness of nasolacrimal massage declines. Out of 8 patients who did not respond to nasolacrimal duct massage and subsequently underwent syringing and probing, seven patients were relieved of their symptoms (Table 3). Thus, the overall success rate of syringing and probing was $87.5 \%$. D. Shivpuri et al (1994) ${ }^{13}$ reported success rate of $91 \%$ with nasolacrimal duct massage in their patients. Nazaullah Khan et al (2006) ${ }^{11}$ who reported success rate of $83.2 \%$. Study done by Qasem Hammory et al (2010) ${ }^{14}$ reported success rate of $82.5 \%$. Kapadia et al (2006) ${ }^{15}$ reported overall success rate was $72 \%$ for syringing and probing. Children aged $<36$ months had a success rate of $78 \%$; children aged $\geq 36$ months had a success rate of $50 \%$. They concluded that age at the time of procedure was a significant risk factor for failed probing. Zwann et al ${ }^{16}$ also reported success rate for syringing and probing about $97 \%$ in $0-12$ months' age group and which declined to $88 \%$ in 13 - 24 months' age group.

\section{CONCLUSION}

With this study, we conclude that nasolacrimal duct massage has a very high success rate and should be started as early as possible to be more effective. The syringing and probing also have high success rates and should be started as early as six months of age to avoid the morbidity of epiphora and risk of dacryocystitis.

\section{REFERENCES}

[1] Robb RM. Congenital nasolacrimal duct Obstruction. Ophthalmology Clinics of North America 2001;14(3):443-6. viii

[2] Kerstein RC. Congenital lacrimal abnormalities In: Principles and practice of ophthalmic plastic and reconstructive surgery. Vol. 2. WB Saunders Company 1996: p. 731-47.

[3] Nelson LR, Calhoun JH, Menduke H. Medical management of congenital nasolacrimal duct obstruction. Ophthalmology 1985;92(9):1187-90. 
[4] Baker JD. Treatment of congenital nasolacrimal system obstruction. J Pediatr Ophthalmol Strabismus 1985;22:34-6.

[5] Casady DR, Meyer DR, Simon JW, et al. Stepwise treatment paradigm for congenital nasolacrimal duct obstruction. Ophthal Plast Reconstr Surg 2006;22(4):243-7.

[6] Katowitz JA, Welsh MG. Timing of initial probing and irrigation in congenital nasolacrimal duct obstruction. Ophthalmology 1987;94(6):698-705.

[7] Stager D, Baker JD, Frey T, et al. Office probing of congenital nasolacrimal duct obstruction. Ophthalmic Surg 1992;23(7):482-4.

[8] Honavar SG, Prakash VE, Rao GN. Outcome of probing for congenital nasolacrimal duct obstruction in older Children. Am J Ophthalmol 2000;130(1):42-8.

[9] Robb RM. Success rates of nasolacrimal duct probing at time intervals after 1 year of age. Ophthalmology 1998;105(7):1307-10.

[10] Crigler LW. The treatment of congenital dacryocystitis. JAMA 1923;81(1):23-4.
[11] Khan N, Khan MN, Jan S, et al. Congenital nasolacrimal duct obstruction: presentation and management. Pak J Ophthalmol 2006;22(2):74-8.

[12] Halipota FM, Dahri GR, Anjum N, et al. Results of lacrimal probing in infants and children. Pak J Ophthalmol 2000;6:47-50.

[13] Shivpuri D, Puri A. Congenital nasolacrimal duct obstruction: the proper technique of massage. Indian Paediatrics 1994;31:337-40.

[14] Hammory Q, Bataineh HA, Nusier Z. Congenital nasolacrimal duct obstruction at prince rashed hospital, Irbid, Jordan. Sudanese Journal of Public Health 2008;3(4):167-9.

[15] Kapadia MK, Freitag SK, Woog JJ. Evaluation and management of congenital nasolacrimal duct obstruction. Otolaryngol Clin North Am 2006;39(5):959-77, vii.

[16] Zwaan J. Treatment of congenital nasolacrimal duct obstruction before and after the age of 1 year. Ophthalmic Surg Lasers 1997;28(11):932-6. 